\title{
Model Studies in Catalysis
}

N. Nilius, T. Risse, S. Schauermann, S. Shaikhutdinov, M. Sterrer, H.-J. Freund*

Fritz Haber Institute of the Max Planck Society, Department of Chemical Physics

Faradayweg 4-6, 14195 Berlin, Germany

*freund@fhi-berlin.mpg.de

\begin{abstract}
We review our approach to model heterogeneous catalysts on the basis of four examples. It is shown that Pd nanoparticles in hydrogenation incorporate hydrogen which turns out to be crucial for the actual hydrogenation step. The second example correlates the structure of vanadia monolayer catalysts with its reactivity in methanol oxidation. Further examples refer to ultrathin oxide film catalysts where the oxide metal interface controls either the charge state of Au particles grown on the film (example 3), and, in the fourth example, the oxide film itself exhibits remarkable CO-oxidation activity which can be traced to a reactive intermediate structure of the ultrathin film.
\end{abstract}

\section{Keywords}

Model Systems, Catalysis, Surface Science, Nanoparticles, Ultrathin Films

\section{Introduction}

Technologically employed disperse metal catalysts consist of metal nanoparticles, which determine the catalytic activity and are anchored onto a morphologically complex mixed oxide support [1, 2]. Almost always, preparation proceeds via wet impregnation from solution. The particles formed are not homogeneous in size and distribution, and are usually characterized via electron microscopy and their chemical reactivity. The catalytic activity is determined by its surface structure, which is difficult to access via techniques of surface physics, since most support materials are insulators. This prohibits the use of techniques involving electrons and ions as information carriers [3-6]. The use of thin, well ordered oxide films as support materials, which do not charge up during measurement, provides an ideal solution to this problem, and allows us to capture some of the complexity represented by technologically employed disperse metal catalysts while allowing the application of the tool box of surface science to study surfaces at atomic detail. 
Fig. 1 shows a schematic diagram of the kind of model systems we have studied and which will be briefly addressed in the present paper.
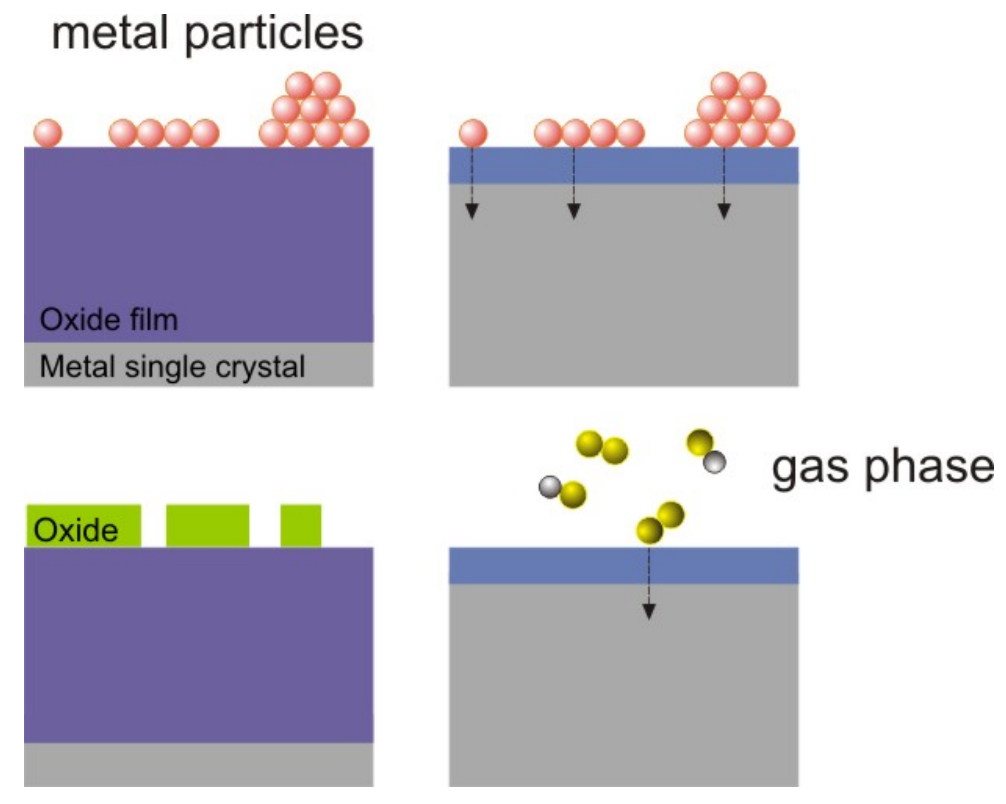

Fig. 1: Schematic representation of classes of model systems

There are two classes of model systems: one, where the goal is to represent a disperse supported metal or a mixed oxide catalyst. Both are shown on the left hand side and are based on the ability to model the bulk or volume of a supporting oxide using thin film techniques. In a second class of model systems, shown on the right hand side, the thickness of the oxide film and the oxide metal interface created by growing the film are used as decisive parameter to control the electronic structure. This may influence either a supported deposit, as, for example, a metal atom or nanoparticle, or the film itself, by the chemical potential of the gas phase, resulting in the formation of a catalytically active phase. The phenomena, observed for this second class of materials are very much influenced by the flexibility, the oxide lattice of a thin film exhibits as compared to the bulk material, and it may provide a new route to catalyst design. However, lattice flexibility is also an important ingredient to understand catalysis by supported nanoparticles, as components of the gas phase may interact very strongly with the nanoparticles and even be incorporated into the nanoparticle at considerably lower temperature when compared with the metal bulk.

The present paper centers around this question and we will show, by virtue of four examples, how the phenomena addressed express themselves.

2 Modeling oxide supported catalysts 
We start with an example, where Pd nanoparticles are deposited on a thick ( 10nm) $\mathrm{Fe}_{3} \mathrm{O}_{4}(111)$ film and we investigate hydrogenation of a simple hydrocarbon molecule such as cis-2-butene [7-11]. We use this molecule to be able to follow certain reaction paths which would be difficult to elucidate with ethene itself, although we assume the same chemistry to apply in both cases [12].

Fig. 2 shows STM images of $\mathrm{Pd}$ nanoparticles on an $\mathrm{Fe}_{3} \mathrm{O}_{4}(111)$ surface. The particles are facetted with (111) and (100) planes, establishing truncated octaedra [13].
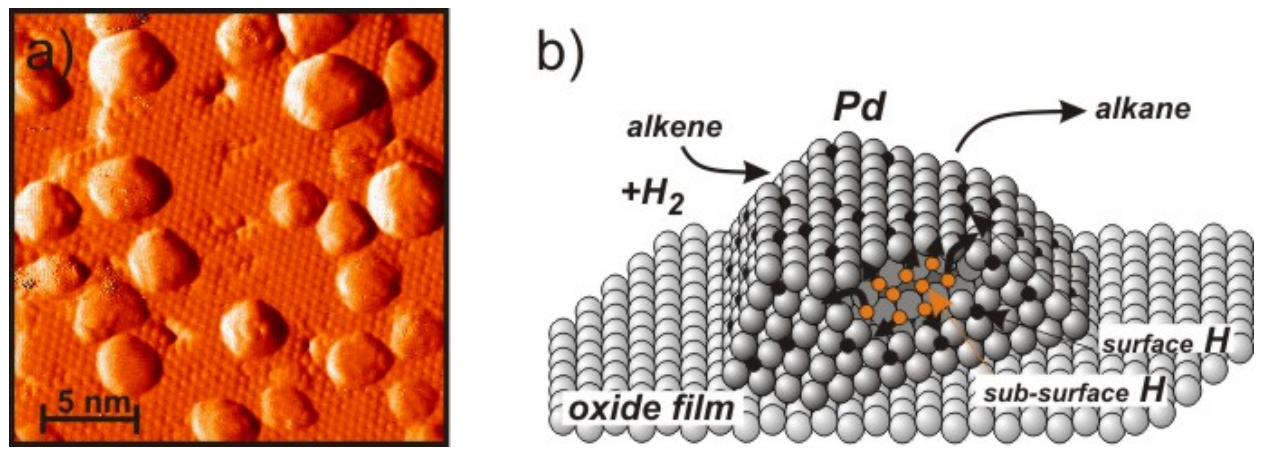

Fig. 2: a) STM image of $\mathrm{Pd}$ nanoparticles on $\mathrm{Fe}_{3} \mathrm{O}_{4}(111)$. The crystallographic facets of the particles are clearly recognizable as is the atomic corrugation of the support. b) Schematic representation of a Pd nanoparticles indicating atomic hydrogen adsorbed on the surface and in the particle.

For Pd on alumina it was even possible to resolve the atomic structure of the facets [14]. Thus, those systems represent model systems, where one would assume that a single crystal metal approach à la Ertl [15] or Somorjai [16] would perfectly apply. However, as will be outlined, this is not the case. Due to the considerably higher flexibility of the lattice of the small particle as compared to a single crystal the interior of the particle actively participates in reactions and, in particular, in hydrogenation reactions by hydrogen accommodation at conditions different from the bulk material [9, 17-20]. Here we will only briefly recapitulate the basis for this statement. First we note, that opposite to a $\operatorname{Pd}(111)$ single crystal, the supported Pd nanoparticles, under molecular beam conditions, fully reproduce, within the accessible pressure regime [21], the results known for technical catalysts [22]. We recall that hydrogenation occurs according to the Horiuti-Polanyi mechanism [23]. As shown in Fig. 3a the key intermediate is represented by a species where the C-C double bond is half hydrogenated on one end and bound to the surface on the other end, i.e. a butyl species for the case of cis-2-butene is formed [24-28]. 

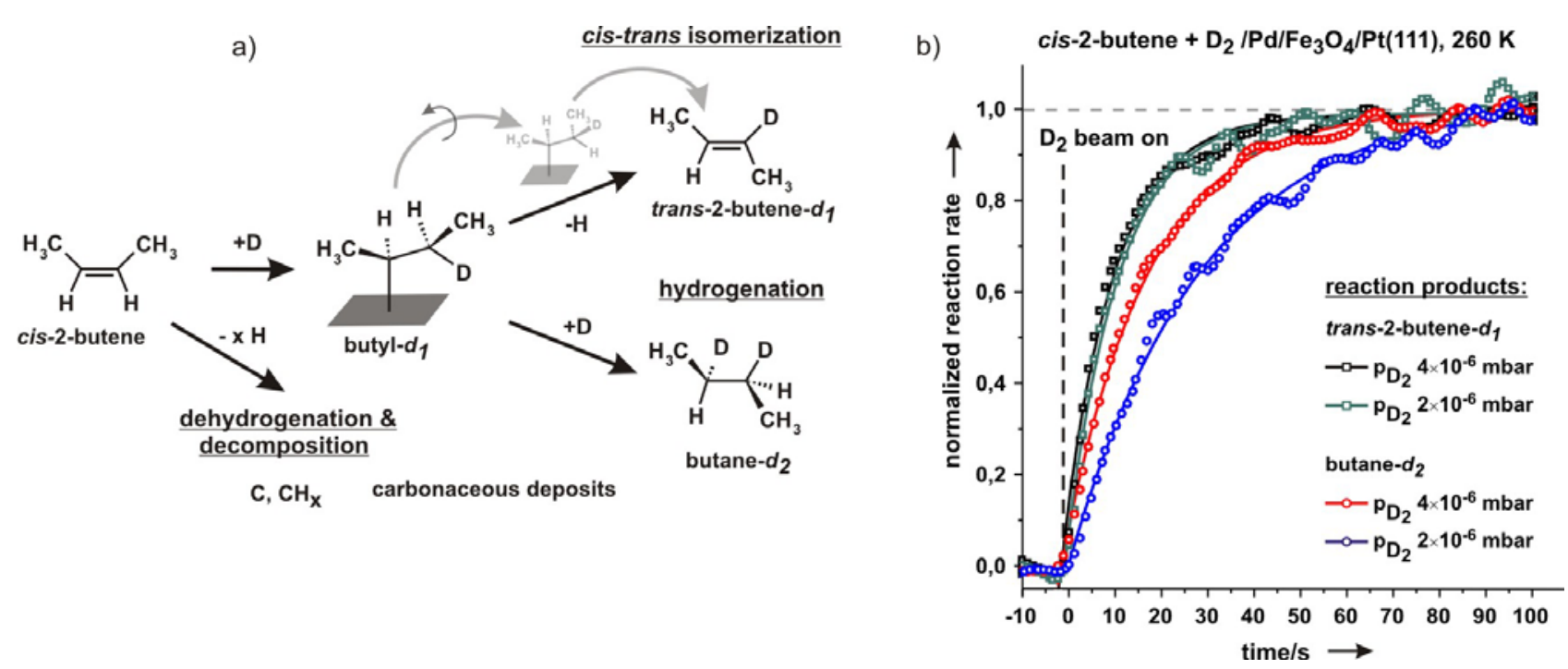

Fig. 3: a) Diagrammatic representation of the various steps following the Horiuti-Polanyi mechanism for alkene hydrogenation, exemplified with cis-butane. The key intermediate is the butyl species from which isomerization and hydrogenation branches out. b) Results of molecular beam experiments for cis-2-butene isomerization as compared to hydrogenation. For details see [8, 9].

This species may than either again dehydrogenate and desorb as trans-2-butene, the stable isomer of cis-2-butene, or may be fully hydrogenated to desorb as butane. Parallel to this, the hydrocarbon may fully dehydrogenate and deposit carbonaceous species on the surface. While, both, isomerization and dehydrogenation, is observed on the $\operatorname{Pd}(111)$ single crystal, the full sustained hydrogenation reaction is not obserbed, however, on the nanoparticles all reactions are observed [17, 29]. Also, only on the nanoparticles sustained catalytic activity has been observed. Recently, we have clearly demonstrated that this is connected with the presence of carbonaceous species which influences the diffusivity of hydrogen from the surface to the sub-surface region of the metal [7-10]. It is the subsurface hydrogen (Fig. 2) that turns out to be key for the hydrogenation reaction. While sub-surface hydrogen has been proposed for both Pd single crystals and Pd nanoparticles, the volume of the Pd single crystal favors the entropy driven dissolution of hydrogen while in a nanoparticle the hydrogen is forced to stay near the surface due to its size and the diffusion barrier of the oxide. How much of the hydrogen is present in the particle, is set by the chemical potential of the gas phase, and due to the higher flexibility of the metal nanoparticle lattice will be different from a single crystal. We have used resonant-nuclear reaction analysis ( $r-N R A$ ) to quantitative determine the amount of surface versus subsurface hydrogen in supported nanoparticles, and used that knowledge to prove the importance of the sub-surface species for the hydrogenation reaction $[9,30]$. One result is shown in Fig. 3b. Here we compare four traces in a set of molecular beam experiments. The conditions for those experiments have been chosen based on the knowledge from $r$ - 
NRA experiments that between the two hydrogen pressures the surface is saturated in hydrogen while the hydrogen content in the particle still strongly varies. Two of the four traces monitor the isomerization reaction (cis-2-butene to trans-2-butene) and the other two the hydrogenation towards butane as recorded via mass-spectrometry. It is quite obvious that the isomerization reaction which is accepted to be a reaction driven by surface hydrogen, does not change with hydrogen pressure, as expected for saturated surface hydrogen coverage. On the other hand, the hydrogenation depends on hydrogen pressure, i.e. hydrogen concentration in the particle. This, clearly, demonstrates the importance of this species for the hydrogenation channel.

In summary, we note on the basis of this example, that, in order to trace results observed on real catalysts it is important to capture some of the complexity of the real system. In the present case it is the size of the metal particle and the presence of the support that is important to understand the elementary processes involved. Here, metal single crystals represent a too simple model system.

The second example is concerned with the reactivity of oxide nanoparticles supported by another oxide material. It is an established concept among catalyst scientists that so called monolayer catalysts, where a reactive oxide, such as vanadia, is supported on a second oxide, such as ceria, exhibits considerably higher activity for methanol oxidation towards formaldehyde. This does not mean that such catalysts may soon replace the iron molybdate based catalysts currently used in industry but it is interesting to try to understand the monolayer catalysts on a more detailed basis and to verify some of the ideas that have been put forward in the catalysis literature. Our studies are mainly based on results reviewed by Israel Wachs [31], who compared vanadia overlayers on a number of support materials, such as $\mathrm{SiO}_{2}, \mathrm{Al}_{2} \mathrm{O}_{3}, \mathrm{ZrO}_{2}, \mathrm{TiO}_{2}$ and $\mathrm{CeO}_{2}$. Plotting the turnover for methanol oxidation to formaldehyde against the electronegativity of the support cations he noticed a non linear increase from $\mathrm{SiO}_{2}$ to $\mathrm{CeO}_{2}$ indicating that the support may play an active role in the process. In a combined experimental and theoretical effort together with Joachim Sauer's group we have studied those systems using the described model catalyst approach [32-42]. We have studied alumina, silica, and ceria as supports for vanadia deposits prepared by physical vapor deposition in an oxygen ambient. Briefly, vanadia grows as threedimensional clusters, both, on alumina and silica from low to high coverage. The vanadium is present in oxidation state (+III) in the volume of the clusters and in oxidation state $(+\mathrm{V})$ at the surface as evidenced by photoelectron spectroscopy and the appearance of vanadyl vibrations which indicate the same surface termination of the clusters as found for 
$\mathrm{V}_{2} \mathrm{O}_{3}(0001)$ surfaces [38]. Those supported clusters oxidize methanol to formaldehyde at about $500 \mathrm{~K}$, independent of vanadia coverage. On the basis of those studies it was possible to reassign the vibrational spectra of supported vanadia and identify vanadia-support interface vibrations that had been previously assigned to vanadyl vibrations of oligomeric vanadia deposits. While on silica and alumina three-dimensional growth of vanadia is observed, on ceria the predicted growth of monomeric, oligomeric and two-dimensional (i.e. monolayer) vanadia is, in fact, observed and interesting correlations with spectroscopic data and reactivity may be drawn.

Fig. 4 shows a combination of STM images, vibrational and photoelectron spectra for vanadia deposits on ceria.
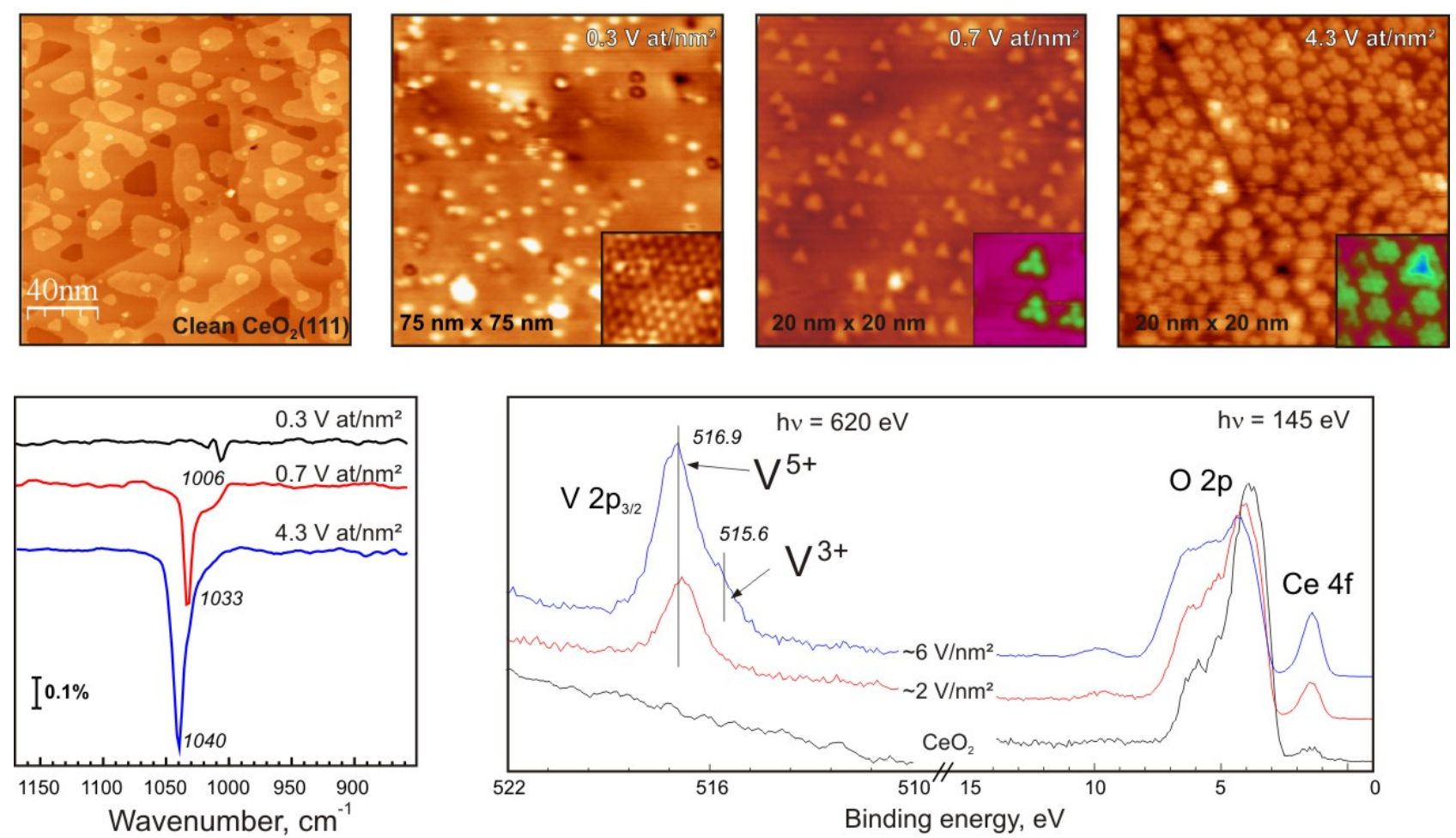

Fig. 4: a) STM images of $\mathrm{CeO}_{2}$ (111) films on $\mathrm{Ru}(0001)$ left (clean), towards the right increasing coverage of vanadium per $\mathrm{nm}^{2}$ in oxygen as given in the images. b) FTIR spectra after vanadia deposition for three different coverages. c) Photoelectron spectra before and after vanadia deposition on $\mathrm{CeO}_{2}(111) / \mathrm{Ru}(0001)$ in the range of $\mathrm{V} 2 \mathrm{p}_{3 / 2}$ and the valance band isomerization taken with synchrotron radiation at BESSY II.

The ceria support was grown as a thin film (thick enough to represent the bulk) [43] on a $\mathrm{Ru}(0001)$ single crystal surface according to a recipe by Mullins et al [44]. and modified in our group.

A large scale image of the ceria film is shown on the far left of Fig. 4. Upon deposition of small amounts of vanadia, small, statistically distributed protrusions are observed which are accompanied by an IRA spectrum indicative of isolated vanadyl groups. Upon increas- 
ing the coverage we see larger protrusions occurring (looking like trimers) which grow into two-dimensional islands with even a second layer on top of them. Parallel to this a shift of the vanadyl frequency to higher values compatible with dipolar coupling in the larger aggregates, and opposite to what was deduced from studies on powders, is observed. This is yet another example where model studies on well defined structures can help to settle spectroscopic assignments. The infrared spectra are indicative of the formation of vanadyl (i.e. $V(+V)$ ) species which is corroborated by chemical shifts in XPS spectra (see Fig. 4). The higher vanadia loadings show the occurrence of $V(+I I I)$ species with the appearance of large aggregates in the STM images. It is interesting to note that parallel to this the UPS spectra show an increasing $\mathrm{Ce}(+\mathrm{III})$ signal near the Fermi energy. This can easily be explained by a redox mechanism upon vanadia adsorption. As the vanadia adopts its $V(+V)$ oxidation state, it reduces the ceria in the film, originally in the $\mathrm{Ce}(+\mathrm{IV})$ state to $\mathrm{Ce}(+\mathrm{III})$. Note, that the small $\mathrm{Ce}(+\mathrm{III})$ signal in the clean film stems from $\mathrm{Ce}(+\mathrm{III})$ at defects (steps and vacancies). We have studied such samples with respect to methanol oxidation to formaldehyde using temperature programmed reaction (TPR). The outcome is interesting but will only be briefly mentioned here $[42,45]$ : While $\mathrm{CeO}_{2}$ is active itself producing formaldehyde near $600 \mathrm{~K}$, a higher loading of vanadia produces a TPR peak below or near $500 \mathrm{~K}$ similar to the larger clusters of vanadia on silica and alumina. For the monomers and small vanadia cluster species, which are not stable to high temperature, a TPR peak of considerably lower temperature $(370 \mathrm{~K})$ is observed. Obviously, such species are more reactive, and this observation can be well explained by theoretical models describing the elementary steps involved. In summary, this is another example where model studies may be employed to reveal detailed structure reactivity relations, hardly possible on powder samples where structure may be deduced, at best, rather indirectly.

\section{Ultrathin film catalysts}

We now move the discussion to the second class of system discussed in the introduction. Here we discuss ultrathin films where we have to consider interaction between the adsorbate on the thin film and the oxide metal support interface.

In order to analyze the situation with the help of simple physical models one has to consider, for example, the physical quantities that determine electron transfer from the metal substrate through the film [46]. This is on one hand the ionization potential to excite an electron from the metal oxide, which is, in general, not simply the work function of the metal, because it will be substantially modified by the presence of the oxide overlayer, and, on the other hand, the electron affinity of the species, adsorbed on the oxide surface, which 
again may be influenced by the interaction with the oxide surfaces. If the energy balance in between those quantities results in an energy gain, then the electron transfer is possible, in principle. However, this is only part of a proper description, because it is not obvious how the quantity would depend on thickness of the film, as the energy balance will only weakly depend on it for very thin films! Of course, in case of films with several nanometer thickness the tunneling probability would simply be zero. But why would an oxide film of three layers differ from one of eight layers with respect to tunneling? The reason is connected with the increased lattice flexibility of very thin films which is altered very rapidly as the film gets thicker, approaching quickly the phonon behavior of the bulk or a bulk terminating surface. In other words, the thin film has the ability to accommodate the charge accumulated through electron transfer by a lattice distortion. A property which a thick film may not exhibit. This phenomenon is called a polaronic distortion and is well known from metal-semiconductor physics. One may use this knowledge to choose combinations of materials in thin oxide film design to produce systems with specific electronic properties with respect to electron transfer, which may in turn lead to specific chemical reactivity. Take, for example, cations, anions or neutrals of one and the same species: They will undergo very different chemical reactions! Therefore, if we succeed in designing specific support systems which promote the formation of specific charge states, we might come to the point where we design catalysts for specific reactions. Of course, under reaction conditions one has to consider the presence of the gas phase as well, when we try to control the electron transfer by materials design because the gas phase determines the chemical potential of a catalyst.

It goes back to Masatake Haruta [47] that small gold particles, not more than 3-4 nm in size, supported on titania exhibit high catalytic activity for a number of interesting chemical reactions. For example, such systems catalyze CO oxidation already at, or even below room temperature, a result that is surprising, as Au is not known for its high chemical reactivity. This is, of course, why Au is called a noble metal. The observations by Haruta have led to many subsequent studies with the goal to unravel the reason for this high reactivity. While there is progress, the problem has not been completely settled [48-50]. One open question concerns the state of charge of the Au particles in its reactive state. Another question refers to the site of reaction on the Au particles. One could imagine that all $\mathrm{Au}$ atoms of the particles show the same reactivity, or alternatively, some specific sites could solely be responsible for the reactivity. For example, the Au atoms at the rim or circumference of the particle, which are in contact with the oxide substrate but are still accessible from the gas phase, could be candidates for such sites. To get closer to a solution, we 
have prepared samples with particles of varying sizes, starting from single Au atoms up to clusters containing 70 atoms or more on a $\mathrm{MgO}(100)$ film composed of three layers.

The oxide film is epitaxially grown on an $\mathrm{Ag}(001)$ surface, covering it completely, and its thickness was chosen such that electrons may be transferred from the MgO/Ag interface to the adsorbed Au particles.

This charge transfer reflects itself in the distribution of individual Au atoms on such an $\mathrm{MgO}(100)$ film $[51,52]$. The Au atoms try to avoid close contact due to their negative charge leading to interatomic repulsion. If more $A u$ is deposited a wetting of the surfaces occurs and a variety of 2-dimensional Au aggregates form, which are stable up to room temperature [53]. Had the experiments been performed on a thick $\mathrm{MgO}(100)$ film the objects would have grown into three dimensional objects instead, as typically found for the growth of metals on oxides. Obviously, thin oxide films can be used as spacers to grow ideally flat metal-insulator structures at smallest dimensions. It is necessary to point out, and to remind us that this statement strongly depends on the system. Had we deposited $\mathrm{Pd}$ instead of $\mathrm{Au}$ onto the thin $\mathrm{MgO}$ film, we would have observed the growth of three dimensional objects in the end, and neutral Pd atoms at the beginning, exhibiting a regular diffusion limited spatial distribution [53]. Therefore, the general statement, often read in literature, that thin films are not to be used as models for bulk oxide materials is very much misleading, as it is strongly dependent on the system studied.

As stated above, clusters of varying sizes were systematically studied. $A u_{1}-A u_{7}$ clusters, which are mainly linear and cluster with sizes between $\mathrm{Au}_{10}$ and $\mathrm{Au}_{20}$, which are twodimensional, have been imaged [54, 55]. Let us consider a larger Au island containing more than 100 Au atoms, conduction images of which are shown in Figure 5 [45, 56]. 

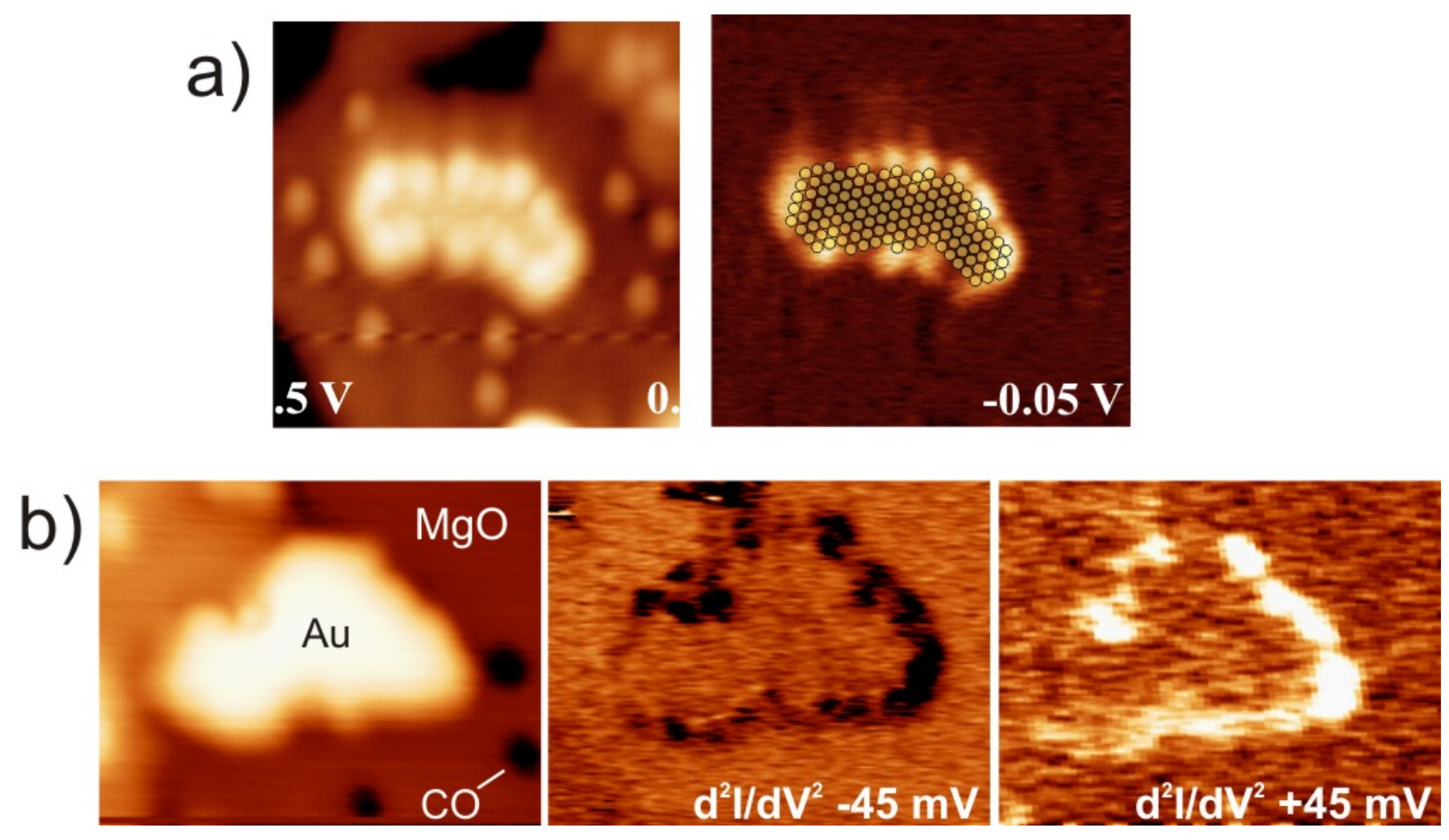

Fig. 5: a) STM images of Au islands on $\mathrm{MgO}(100)$ trilayer film before CO exposure as topographic image (left panel) and conductance image empathizing the rim (right panel). A schematic drawing of the islands topography is overlaid. b) STM image of a Au island on a trilayer $\mathrm{MgO}(100)$ film after exposure to CO (left panel). The two panels on the right show images taken at $\pm 45 \mathrm{mV}$ tunneling voltage using the second derivative. These are conditions to image tunneling losses (inelastic electron tunneling spectroscopy IETS). The voltage corresponds to the hindered rotation of adsorbed CO. A prerequisite for meaningful IETS imaging is that one observes reversed contrast for the loss and gain voltages [45].

Those images may well be simulated by calculations of two dimensional Au islands containing edges and kinks. It turns out that the charge is mainly localized at the edge and preferentially at kinks of the island. Those are positions where acceptor molecules such as $\mathrm{CO}$ and $\mathrm{O}_{2}$ will bind because the Au atoms are coordinatively unsaturated. Figure 5 shows experimental evidence for this: On the left, a topographic STM image of a randomly chosen island that was exposed to $\mathrm{CO}$ is shown, and on the right the same island is imaged in a mode (second derivative) that allows for detection of inelastic losses in the tunneling current $[42,45]$. In this particular case the characteristic frustrated rotation of adsorbed carbon monoxide at $45 \mathrm{meV}$ excitation energy has been probed and used for imaging. In the images one finds the vibration, both as gain (bright) and loss (dark) (processes that may both happen during inelastic tunneling) only at the rim of the island, illustrating and identifying the preferential adsorption sites of $\mathrm{CO}$ molecules. One may therefore consider a scenario, when it comes to $\mathrm{CO}$ oxidation, where both molecules, $\mathrm{CO}$ and $\mathrm{O}_{2}$ bind to the cluster rim, and $\mathrm{O}_{2}$ reacts either directly or after dissociation with co-adsorbed $\mathrm{CO}$ to carbon dioxide. 
Strong Metal Support Interaction (SMSI) observed with particular catalyst systems, in which metal particles (such as $\mathrm{Pd}$ and $\mathrm{Pt}$ ) are strongly interacting with a reducible support (such as titania), and are covered by a thin oxide film upon heating to elevated temperature $[56,57]$ usually show reduced catalytic activity. The oxide film leads to a strong attenuation of adsorption capacity and, consequently, to a deactivation of the system. There have been many attempts to elucidate, even on model system, the nature of the migrating oxide film. The best studied system is $\mathrm{Pt} / \mathrm{TiO}_{2}(110)$, but even in this case the attempts have been rather unsuccessful. Very recently, we succeeded in preparing such a SMSI model system for which we are able to identify atomic structure of the encapsulated oxide film. The system is $\mathrm{Pt}$ supported on a $\mathrm{Fe}_{3} \mathrm{O}_{4}(111)$ film grown on a $\mathrm{Pt}(111)$ single crystal $[58,59]$.

Figure 6 shows an STM image of this system after heating it to $850 \mathrm{~K}$. After this treatment the CO adsorption capacity is drastically reduced which is typical for a SMSI effect. A close look at the STM images reveals well structured and facetted nanoparticles. 
a)

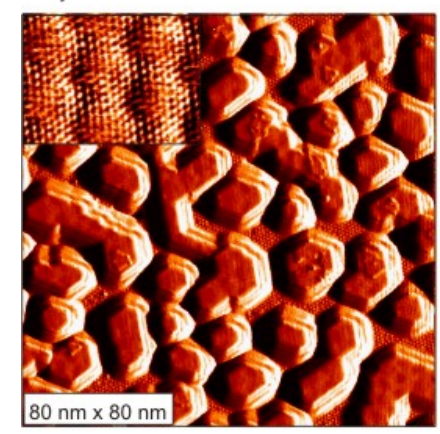

b)

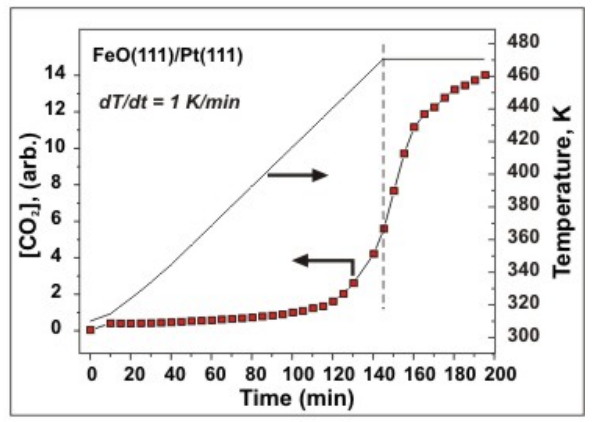

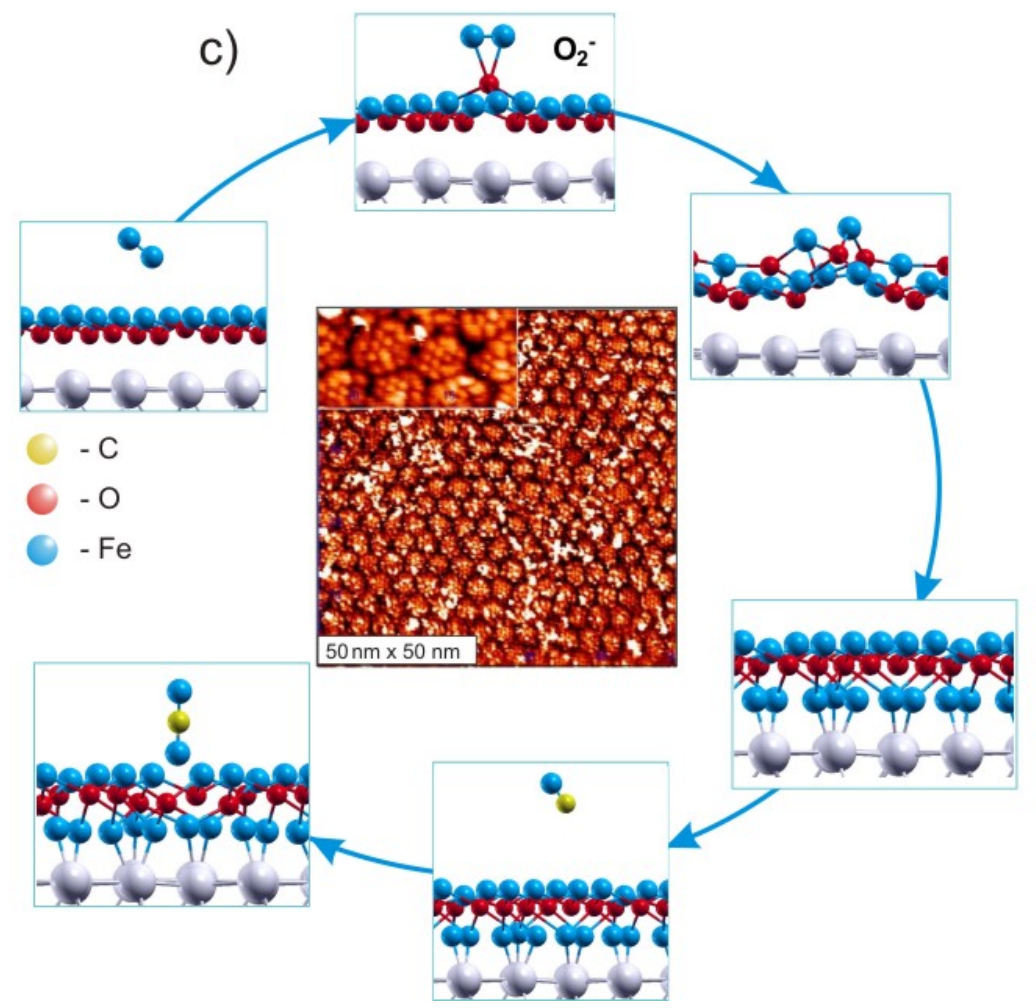

Fig. 6: a) STM image for Pt particles on $\mathrm{Fe}_{3} \mathrm{O}_{4}(111)$. The inset shows the atomic resolution image taken on the top facet of one of the Pt particle. b) CO oxidation on FeO(111)/Pt(111) as a function of time and temperatures $(1 \mathrm{~K} / \mathrm{min})$. The dotted line indicates the time when the temperature was held constant. c) STM image of the active tri-layer- $\mathrm{FeO}_{2-x}$-phase. The inset shows a high resolution image [60]. The panels surrounding the image represent the individual steps in forming the active phase starting from FeO(111)/Pt(111), and its reaction with $\mathrm{CO}$ to form $\mathrm{CO}_{2}$, as revealed by density functional calculations [60, 61].

Moreover, atomically resolved images reveal corrugation that does not stem from Pt but rather from a well ordered double-layer $\mathrm{FeO}(111)$ film, well described and characterized in the literature [14, 62-65]. As the oxide film covering Pt particles has been identified one may reduce the complexity of the model system by studying the properties of the bilayer $\mathrm{FeO}(111)$ film on a $\mathrm{Pt}(111)$ single crystal. Its structure has been studied in detail and characterized at the atomic level [14, 62-65]. The $\sim 10 \%$ misfit between the FeO(111) lattice constant and that of $\mathrm{Pt}(111)$ gives rise to a typical Moiré pattern in the STM image. This film is unreactive under ultrahigh vacuum conditions [66]. The situation changes, however, 
dramatically if one tests the system with respect to CO oxidation at ambient conditions (1 atm) in a reactor $[58,61,66]$ with careful control of the relative amounts of oxygen (one part, 20 mbar), carbon monoxide (two parts, 40 mbar) and helium as buffer gas. If one ramps the temperature linear with $1 \mathrm{~K}$ per minute from $300 \mathrm{~K}$ to $455 \mathrm{~K}$, CO oxidation ignites at $430 \mathrm{~K}$.

The interesting observation is that this FeO/Pt(111) system at this temperature is by more than an order of magnitude more reactive than clean platinum. Usually, SMSI leads to an attenuated activity while here we observe a strong enhancement! Further studies as a function of different gas compositions, as well as thermal desorption studies, STM investigations and detailed DFT model calculations reveal an interesting scenario that allows us to understand this phenomenon [61].

The scenario is depicted in Figure 6. The gas phase sets the chemical potential of the system. The shown steps are based on density functional calculations. Oxygen interacts with the double layer FeO film on $\mathrm{Pt}(111)$ by pulling an iron atom up above the oxygen layer. This lowers the work function at the interface locally to allow for an electron transfer towards oxygen accompanied by the formation of a transient $\mathrm{O}_{2}{ }^{-}$molecule which dissociates and results at higher oxygen coverage in the formation of a local O-Fe-O trilayer. There are, indeed a number of experimental evidence for the existence of such a trilayer. The middle panel in Figure 6 shows an STM image of such a trilayer formed in situ at elevated $\mathrm{O}_{2}$ pressure in a microscope $[60,61]$. Its appearance is in particular determined by the Moiré structure of the FeO double layer and fills 80 - $90 \%$ of the surface as thermal desorption spectra indicate. The images are completely consistent with the structure suggested by the calculation, although the latter does not reproduce the patched morphology due to the enormous size of the unit cell, which was impossible to implement, but necessary to fully reproduce the details. Nevertheless, if the trilayer is exposed to carbon monoxide the trilayer oxidizes the incoming $\mathrm{CO}$ to $\mathrm{CO}_{2}$ via an Eley Rideal mechanism leaving behind an oxygen vacancy in the film. At sufficiently high oxygen pressure the oxygen vacancy is filled again and the trilayer is sustained. If, however, the gas phase is oxygen poor the reaction finally stops because the trilayer is destroyed. Experimentally, we have confirmed [67] that the iron oxide film dewets the Pt(111) surface under CO pool reaction conditions by forming small iron oxide particles, leaving $\operatorname{Pt}(111)$ surface under open which then determines the reactivity of the systems. Heating the dewetted surface in vacuum again leads to the formation of the FeO double layer, which then, at higher oxygen pressure, may be transformed into the trilayer again. 
Summarizing, we are in a position to understand the phenomena in this case on a similar basis as in the first examples on supported small metal clusters, as the electron transfer to oxygen is the key step to initiate the process. Superficially, we may come to the conclusion that we have identified a new concept to look at catalytic systems. Closer inspection reveals that this concept has been used in the late forties by Cabrera and Mott [68] to understand metal oxidation and in the fifties and sixties by F. Vol'kenshtein to explain catalytic activity [69]. This concept has been revived in the late 1980 is by Frost [70] and discussed by Boudart [71] and Ponec [72] subsequently. It was eventually forgotten and not followed up, probably because tools to study systematically such systems at the atomic level were not yet available. Time has come now!

\section{Synopsis}

Combined experimental and theoretical model studies are successful in disentangling structure-spectroscopy and structure-reactivity relationships as demonstrated for a hydrogenation and oxidation reaction. Model systems may be characterized at the atomic level experimentally, which allows for direct comparison with theoretical modeling and allows useful correlations with systems of practical relevance. Thin oxide films on metal substrates represent an interesting and promising material combination. It is possible to use well known concepts from semiconductor physics to understand the underlying principles and to use them to design model systems to get insight into elementary questions in catalysis. In both examples discussed electron transfer determines reactivity. It is quite possible to think about materials combinations which would favor electron transfer for specific molecules and induced specific and selective reactions. Maybe that these new (old) concepts could be used as a guideline to design catalysts. It is important to note that it is crucial to have appropriate experimental techniques at ones disposal. The design of a useful set of experimental techniques is a key goal of experimental research.

\section{Acknowledgment}

Many fruitful and illuminating discussions with our partners in theory: Hannu Häkkinen, Gianfranco Pacchioni, and Joachim Sauer are gratefully acknowledged. We thank the German Science Foundation through the Cluster of Excellence UniCat and the Fonds der Chemischen Industrie for support. 


\section{References:}

[1] G. Ertl, H. Knözinger, F. Schüth, J. Weitkamp, in: Handbook of Heterogeneous Catalysis, Vol. 4, (Wiley-VCH Verlag GmbH \& Co. KGaA, Weinheim, 2008).

[2] G. Ertl, H.-J. Freund, Phys. Today 52 (1999) 32-38.

[3] H.-J. Freund, Angew. Chem. Int. Ed. 36 (1997) 452-475.

[4] H.-J. Freund, Surf. Sci. 500 (2002) 271-299.

[5] H.-J. Freund, H. Kuhlenbeck, V. Staemmler, Rep. Progr. Phys. 59 (1996) 283-347.

[6] H.-J. Freund, D. W. Goodman, in: Handbook of Heterogeneous Catalysis, G. Ertl, H. Knözinger, F. Schüth, J. Weitkamp (Wiley-VCH Verlagsgesellschaft mbH, Weinheim, 2007), chap.

[7] B. Brandt, W. Ludwig, J.-H. Fischer, J. Libuda, F. Zaera, S. Schauermann, J. Catal. 265 (2009) 191-198.

[8] B. Brandt, J.-H. Fischer, W. Ludwig, J. Libuda, F. Zaera, S. Schauermann, H.-J. Freund, J. Phys. Chem. C 112 (2008) 11408-11420.

[9] M. Wilde, K. Fukutani, W. Ludwig, B. Brandt, J.-H. Fischer, S. Schauermann, H. J. Freund, Angew. Chem. Int. Ed. 47 (2008) 9289-9293.

[10] S. Schauermann, K. M. Neyman, Angew. Chem. Int. Ed. in press (2010)

[11] W. Ludwig, A. Savara, S. Schauermann, Dalton Trans. in press (2010)

[12] G. Rupprechter, H. Unterhalt, M. Morkel, P. Galletto, L. Hu, H.-J. Freund, Surf. Sci. 502-503 (2002) 109.

[13] R. Meyer, S. Shaikhutdinov, H. J. Freund, Z. Phys. Chem. 218 (2004) 905-914.

[14] K. H. Hansen, T. Worren, S. Stempel, E. Lægsgaard, M. Bäumer, H. J. Freund, F. Besenbacher, I. Stensgaard, Phys. Rev. Lett. 83 (1999) 4120.

[15] G. Ertl, Reactions at Solid Surfaces (John Wiley \& Sons, Hoboken, 2009).

[16] G. A. Somorjai, Introduction to Surface Chemistry and Catalysis (John Wiley \& Sons, Inc., New York, 1994).

[17] A. M. Doyle, S. Shaikhutdinov, S. D. Jackson, H.-J. Freund, Angew. Chem., Intern. Ed. 42 (2003) 5240.

[18] A. M. Doyle, S. Shaikhutdinov, H. J. Freund, Angew. Chem. Int. Ed. 44 (2005) 629631.

[19] T. Schalow, M. Laurin, B. Brandt, S. Schauermann, S. Guimond, H. Kuhlenbeck, D. Starr, S. Shaikhutdinov, J. Libuda, H. J. Freund, Angew. Chem. 117 (2005) 77737777.

[20] D. Teschner, J. Borsodi, A. Wootsch, Z. Révay, M. Hävecker, A. Knop-Gericke, S. D. Jackson, R. Schlögl, Science 320 (2008) 86-89. 
[21] W. Ludwig, A. Savara, S. Schauermann, H. J. Freund, Chem. Phys. Chem. submitted (2010)

[22] J. A. Dumasic, D. F. Rudd, L. M. Aparicio, The Microkinetics of Heterogeneous Catalysis (ACS, Washington, 1993).

[23] J. Horiuti, M. Polanyi, Trans. Faraday Soc. 30 (1934) 1164.

[24] F. Zaera, Prog. Surf. Sci. 69 (2001) 1.

[25] Z. Ma, F. Zaera, Surf. Sci. Rep. 61 (2006) 229.

[26] F. Zaera, Chem. Rev. 95 (1995) 2651.

[27] F. Zaera, Acc. Chem. Res. 25 (1992) 260.

[28] F. Zaera, Langmuir 12 (1996) 88.

[29] A. M. Doyle, S. K. Shaikhutdinov, H. J. Freund, Angew. Chem., Int. Ed. 44 (2005) 629.

[30] M. Wilde, K. Fukutani, M. Naschitzki, H. J. Freund, Phys. Rev. B 77 (2008) 113412.

[31] I. E. Wachs, Catal. Today 100 (2005) 79-94.

[32] N. Magg, J. B. Giorgi, T. Schroeder, M. Bäumer, H. J. Freund, J. Phys. Chem. B 106 (2002) 8756-8761.

[33] N. Magg, B. Immaraporn, J. Giorgi, T. Schroeder, M. Bäumer, J. Döbler, Z. Wu, E. Kondratenko, M. Cherian, M. Baerns, P. C. Stair, J. Sauer, H.-J. Freund, J. Catal. 226 (2004) 88-100.

[34] S. Guimond, M. Abu Haija, S. Kaya, J. Lu, J. Weissenrieder, S. Shaikhutdinov, H. Kuhlenbeck, H.-J. Freund, J. Döbler, J. Sauer, Top. Catal. 38 (2006) 117-125.

[35] S. Kaya, Y. N. Sun, J. Weissenrieder, D. Stacchiola, S. Shaikhutdinov, H. J. Freund, J. Phys. Chem. C 111 (2007) 5337-5344.

[36] S. Guimond, J. M. Sturm, D. Göbke, Y. Romanyshyn, M. Naschitzki, H. Kuhlenbeck, H.-J. Freund, J. Phys. Chem. C 112 (2008) 11835-11846.

[37] Y. Romanyshyn, S. Guimond, H. Kuhlenbeck, S. Kaya, R. P. Blum, H. Niehus, S. Shaikhutdinov, M. Simic-Milosevic, N. Nilius, H. J. Freund, M. V. GandugliaPirovano, R. Fortrie, J. Döbler, J. Sauer, Top. Catal. 50 (2008) 106-115.

[38] D. Göbke, Y. Romanyshyn, S. Guimond, J. M. Sturm, H. Kuhlenbeck, J. Döbler, U. Reinhardt, M. V. Ganduglia-Pirovano, J. Sauer, H. J. Freund, Angew. Chem. Int. Ed. 48 (2009) 3695-3698.

[39] J. M. Sturm, D. Göbke, H. Kuhlenbeck, J. Döbler, U. Reinhardt, M. V. GandugliaPirovano, J. Sauer, H. J. Freund, Phys. Chem. Chem. Phys. 11 (2009) 3290 - 3299.

[40] M. Baron, O. Bondarchuk, D. Stacchiola, S. Shaikhutdinov, H. J. Freund, J. Phys. Chem. C 113 (2009) 6042-6049. 
[41] H. L. Abbott, A. Uhl, M. Baron, Y. Lei, R. J. Meyer, D. J. Stacchiola, O. Bondarchuk, S. Shaikhutdinov, H. J. Freund, J. Catal. In Press, Corrected Proof (2010)

[42] M. V. Ganduglia-Pirovano, C. Popa, J. Sauer, H. Abbott, A. Uhl, M. Baron, D. Stacchiola, O. Bondarchuk, S. Shaikhutdinov, H.-J. Freund, J. Am. Chem. Soc. 132 (2010) 2345-2349.

[43] J. L. Lu, H. J. Gao, S. Shaikhutdinov, H. J. Freund, Surf. Sci. 600 (2006) 50045010.

[44] D. R. Mullins, P. V. Radulovic, S. H. Overbury, Surf. Sci. 429 (1999) 186-198.

[45] X. Lin, B. Yang, H.-M. Benia, P. Myrach, M. Yulikov, A. Aumer, M. Brown, M. Sterrer, O. Bondarchuk, E. Kieseritzky, J. Rocker, T. Risse, H. Gao, N. Nilius, H. J. Freund, J. Am. Chem. Soc. in press (2010)

[46] L. Giordano, U. Martinez, S. Sicolo, G. Pacchioni, The Journal of Chemical Physics 127 (2007) 144713-144719.

[47] M. Haruta, Cattech 6 (2002) 102-115.

[48] T. Risse, S. Shaikhutdinov, N. Nilius, M. Sterrer, H.-J. Freund, Acc. Chem. Res. 41 (2008) 949-956.

[49] G. J. Hutchings, M. Brust, H. Schmidbaur, Chem. Soc. Rev. 37 (2008) 1759 - 1765.

[50] R. Meyer, C. Lemire, S. Shaikhutdinov, H.-J. Freund, Gold Bulletin 37 (2004) 72124.

[51] M. Sterrer, T. Risse, L. Giordano, M. Heyde, N. Nilius, H. P. Rust, G. Pacchioni, H.J. Freund, Angew. Chem. Int. Ed. 46 (2007) 8703-8706.

[52] M. Sterrer, T. Risse, U. Martinez Pozzoni, L. Giordano, M. Heyde, H.-P. Rust, G. Pacchioni, H.-J. Freund, Phys. Rev. Lett. 98 (2007) 096107.

[53] M. Sterrer, T. Risse, M. Heyde, H.-P. Rust, H.-J. Freund, Phys. Rev. Lett. 98 (2007) 206103-206104.

[54] V. Simic-Milosevic, M. Heyde, N. Nilius, T. Koenig, H. P. Rust, M. Sterrer, T. Risse, H. J. Freund, L. Giordano, G. Pacchioni, J. Am. Chem. Soc. 130 (2008) 7814-7815.

[55] V. Simic-Milosevic, M. Heyde, X. Lin, T. König, H.-P. Rust, M. Sterrer, T. Risse, N. Nilius, H.-J. Freund, L. Giordano, G. Pacchioni, Phys. Rev. B 78 (2008) 235429.

[56] X. Lin, N. Nilius, M. Sterrer, P. Koskinen, H. Häkkinen, H.-J. Freund, Phys. Rev. B 81 (2010) 153406.

[57] F. C. M. J. M. Van Delft, B. E. Nieuwenhuys, Solid State Ionics 16 (1985) 233-240.

[58] Z. H. Qin, M. Lewandowski, Y. N. Sun, S. Shaikhutdinov, H. J. Freund, J. Phys. Chem. C 112 (2008) 10209-10213. 
[59] Z. H. Qin, M. Lewandowski, Y. N. Sun, S. Shaikhutdinov, H. J. Freund, J. Phys.: Condens. Matter 21 (2009) 134019.

[60] M. Lewandowski, Thesis (Technical University, Berlin, 2011).

[61] Y. N. Sun, L. Giordano, J. Goniakowski, M. Lewandowski, Z. H. Qin, C. Noguera, S. Shaikhutdinov, G. Pacchioni, H. J. Freund, Angew. Chem. Int. Ed. accepted

[62] H. C. Galloway, J. J. Benítez, M. Salmeron, Surf. Sci. 298 (1993) 127-133.

[63] W. Weiss, A. Barbieri, M. A. Van Hove, G. A. Somorjai, Phys. Rev. Lett. 71 (1993) 1848.

[64] G. H. Vurens, V. Maurice, M. Salmeron, G. A. Somorjai, Surf. Sci. 268 (1992) 170.

[65] G. H. Vurens, M. Salmeron, G. A. Somorjai, Surf. Sci. 201 (1988) 129.

[66] Y. N. Sun, Z. H. Qin, M. Lewandowski, E. Carrasco, M. Sterrer, S. Shaikhutdinov, H. J. Freund, J. Catal. 266 (2009) 359-368.

[67] Y. N. Sun, Z. H. Qin, M. Lewandowski, S. Kaya, S. Shaikhutdinov, H. J. Freund, Catal. Lett. 126 (2008) 31-35.

[68] N. Cabrera, N. F. Mott, Rep. Progr. Phys. 12 (1948) 163.

[69] F. F. Vol'kenshtein, Russ. Chem. Rev. 35 (1966) 537.

[70] J. C. Frost, Nature 334 (1988) 577-580.

[71] M. Boudart, Catal. Lett. 13 (1992) 153-154.

[72] V. Ponec, Catal. Lett. 11 (1991) 249-250. 